\title{
The Bracken Cairn
}

\section{A Prehistoric Burial}

by D. R. King (Archeological Assistant, Glenbow Foundation, Calgary, Alta.)

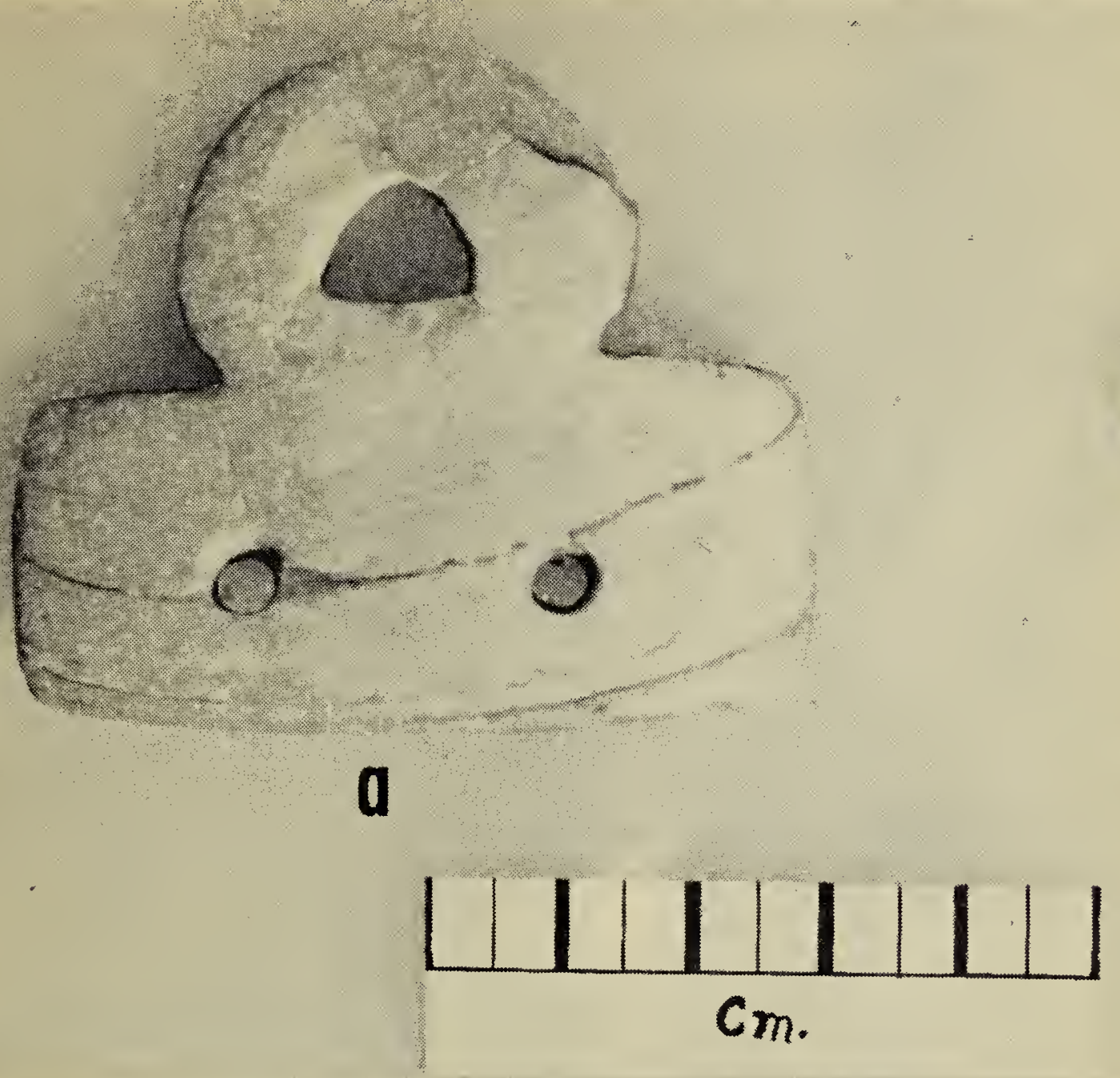

Fig. 1. Shell gorget and bead from the Bracken Cairn.

\section{FOREWORD}

While this report has been compiled fully in most instances, it contains many gaps, due mainly to the fact that the site was not systematically excavated, but rather simply dug up by interested collectors. Therefore the material must be related to mental notes of the excavators, and leaves much to be desired. Nevertheless the finders did all in their power to remember and record the sequence and provenience. A lapse in time of two decades from the first excavation to the final removal of all material has made it impossible to accurately analyse the burial, inasmuch as most of the osteological material was badly damaged by backfilling with rocks, premature exposure to air, disturbance of the natural hardpan matrix, and unorthodox excavation methods.

The diggers themselves are the first to admit regret concerning this un- fortunate situation, but owing to lack of experienced help and counsel at the time of discovery, they proceeded in an unscientific manner. However since responsible bodies have become extant in latter years, they have willingly and gladly placed all material and information at the disposal of the author, in the hope that everything of value may be recovered despite their unsystematic methods. This treatment of an archeological site shows how necessary is the skilled scientific approach to excavation, and it is my earnest hope that the readers may take warning and avoid such practices in the future.

\section{HISTORY OF THE SITE}

In the summer of $1936 \mathrm{Mrs}$. Laura Wright and a group of rock collectors, wandering along the hills above the Frenchman River in the southwest corner of Saskatchewan, came upon a low pile of stones at the top of a 
N
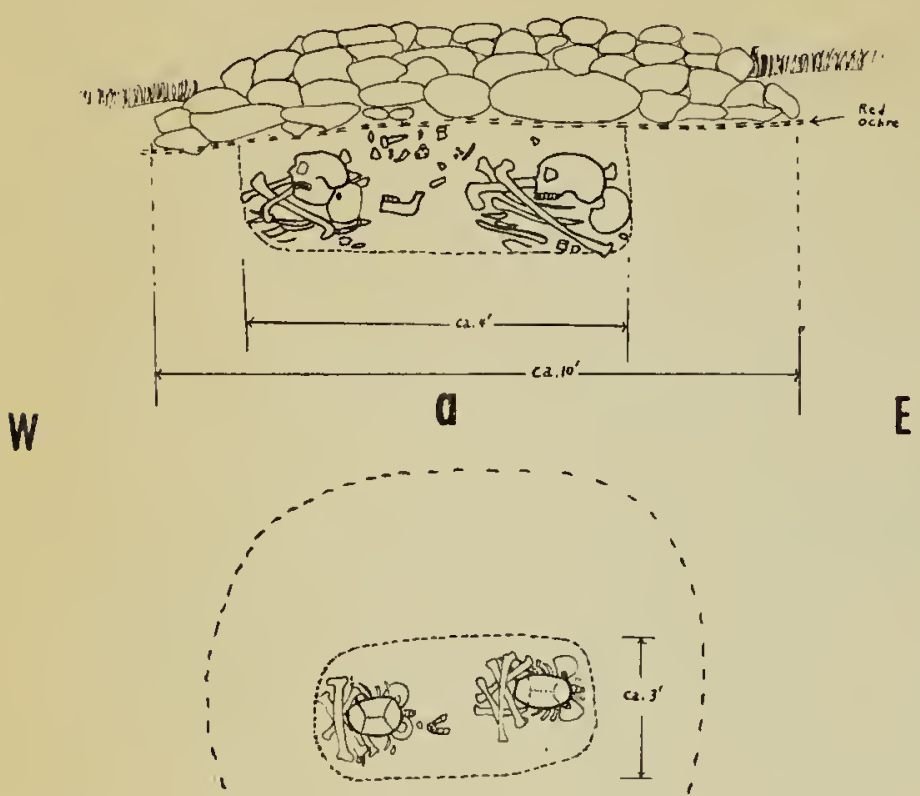

Arter Wright

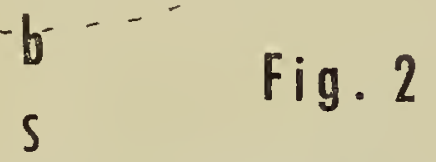

Fig. 2. Bracken Caim (from sketches by Mrs. Laura Wright).

hill. The stones were deeply imbedded in the sod, but at the northwest site they found some pieces of shell in the dirt thrown out of a gopher hole. When cemented together the pieces formed the largesit part of a shell gorget, with only a small portion missing. (Fig. 1-a). Other things distracted the searchers and it was not for 12 years that the cairn was next visited.

In May of 1948 they returned. Mrs. Wright and her brother, Melvin Bakkan, rode back to the hill. Their only tools were a jack knife and a screw driver, and with these implements they began hacking out the sod and roots filling the interstices of the cairn. Chips of chert and flint appeared, with a human tooth and other small human and animal bones. Just below grass roots they came to a layer of reddish sand, quite foreign to the natural soil. This sand, in an even layer about a half an inch in thickness, seemed to cover the entire area. The hardness of the ground made digging difficult and slow with the crude tools, but stone by stone they worked downward. Deep inside the pile they found a stone much larger than the rest, and when this was removed, the top of a human skull was exposed. It took two hours of careful picking to remove the skull from the cement-like earth. Darkness forced a halt to the work, so when the piece was removed they covered the hole with stones and retired.

The following week they returned to the site and resumed digging. Beneath the skull they found the earth had a dark red colour. The bones below were sitained and coated dark red. The whole skeleton was exposed in a compact pile, except for the mandible. The leg bones were crossed and the skull, facing west, lay between the ribs and the pelvic bones.

When the grave contents had been removed, the pair began digging carefully toward the western pontion of the cairn. A bone awl was the first item, then three shell beads, two portions of hollowed deer antlers, and two more bone pendants. Darkness again forced cessation of work, and having not yet found the human mandible, they decided to try again later.

On the third day they recovered the missing mandible, over a foot from the rest of the skeleton. Near it were a number of mammal teeth. More bone pendant's and worked pieces of stone came to light. Here also they uncovered a small stone pestle and perhaps most significant, a projectile point, along with other artifacts and bones.

Pure chance prompited them to dig a little further west, where they came upon the second skeleton, also complete. This skeleton also faced the west, sitting in almost exactly the same position as the first, and the bones were the same reddish colour.

They placed the long bones and small bones in $\mathrm{a}$ box and reburied them, keeping only the artifacts and the skulls. These they took to the river and washed, losing much of the colour in the process.

It is fortunate that Mrs. Wright had the foresight to keep a record of the digging, with accurate sketches of pertinent skeletal positions. (Figs. $2 \mathrm{a}$ and $2 \mathrm{~b}$ ). At my request she sent the complete contents of the cairn for preliminary analysis. Following this in 1957 the specimens were sent to the Saskatchewan Museum of Natural History, where Dr. Robert W. Nero was to help Mrs. Wright prepare a report on the cairn material. Dr. Nero later and at my request generously turned the drafting 
of this report over to me and promptly shipped the specimens back to mè, including his notes.

As best as can be determined or deduced the following describes the nature of the burial and its contents:

\section{NATURE OF INTERMENT}

When first discovered, the Bracken Cairn was covered by a pile of fieldstones partly overgrown with grass. That artifacts were found near the top would suggest that they were placed over the bodies at the time of buriel (Smith. Inst., 1910:361). A thick layer of red ochre was spread over the filled grave, beneaith the rocks, and through time the colour has leached down, staining many of the bones and even some of the artifacts. The abundance of ochre on some bones suggests the possibility that the bones were painted after the flesh had gone. This in turn suggests a reburial or 'bundle burial,' in which the bones from a previously 'scaffoldburied' body were later gathered and reburied in the cairn.

The position of the bones in a pile substantiates this hyporthesis, although the bodies have been buried in a sitting position. Reburial is known to have been a common custom of the Plains tribes (Lowie, 1954:86).

The placement of the mandible apart from the skull suggests to me that the burials took place at different times, and that the mandible was disturbed while the second body or bundle was being placed in position, for here again is a common practice on the Plains, to bury or re-bury the bones of relatives in the same excavation or site (Smith. Inst., 1910: 104).

There is some possibility that the mandible was displaced by burrowing animals, but Mrs. Wright states that the soil around it was just as hard and compact as that in the rest of the grave, and indistinguishable in texture. A burrow of any kind would show traces of soil differences and coloration, and an animal large enough to move a mandible fifteen inches would disturb more than one portion of the burial.

By comparing the Bracken Cairn mode of burial with the above-mentioned Plains customs, I am attempting only to show that such practices were not necessarily a departure from the norm, and it is not my intention to attempt to identify the Bracken people with any of the later historic tribes. I am merely outlining various burial habits which would seem to explain the obvious questions posed.

\section{HUMAN SKELETAL REMAINS}

The two adult skulls are dissimilar, BG-1 having markedly open sutures and a much more globular shape than BG-2, in which the coronal and saggital sutures are completely closed and the lambdoid and squamous sutures very nearly so. The traits point to a difference in age, and possibly sex, although sex and race have very little or no influence on suture closure (Todd and Lyon, 1954): In the case of the Bracken skulls, age estimations are based on ectocranial fusion, which prognesses at a slower rate than endocranial closure, and is therefore not so reliable as an indicator.

Three vault sutures only were considered: saggital, coronal and lambdoid; and when compared according to the graphs supplied in the reference (Todd and Lyon, 1954), produced the following results:

BG-1

\begin{tabular}{lcc}
\hline Suture & $\begin{array}{c}\text { Degree of } \\
\text { Closure }\end{array}$ & $\begin{array}{c}\text { Estimated } \\
\text { Age at Death }\end{array}$ \\
\hline Saggital & $1 / 2$ & \\
Coronal & $1 / 4$ & 27 \\
Lambdoid & $1 / 4$ & $26-27$ \\
& BG-2 & $27-28$ \\
Saggital & complete & 35 up \\
Coronal & $3 / 4$ & 32 \\
Lambdoid & $3 / 4$ & 36
\end{tabular}

The man would therefore have been between the ages of 26 ito 28 when he died.

The woman's estimated age would appear to be anywhere from 32 to 36 or possibly more. Inasmuch as ectocranial sutures often do not ever completely fuse or close, these figures then only become suggestive.

Contents of the burial lead one to suspect that one of the skulls is that of an adult male, the other an adult female. Some attempts to subsitantiate this idea were carried out with constant reference to the listed texts (Todd and Lyon, 1954). Following a progressive check list, it is possible to note the differences in bone structure. For instance, BG-1 appears to correspond very closely with the 


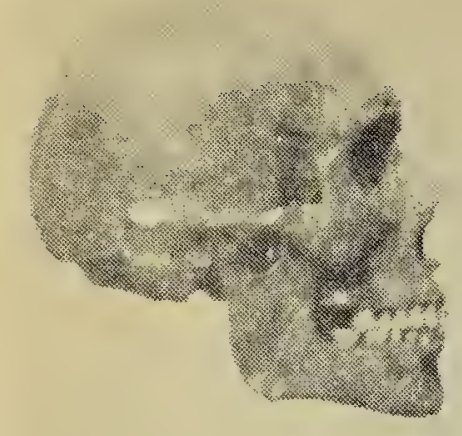

a
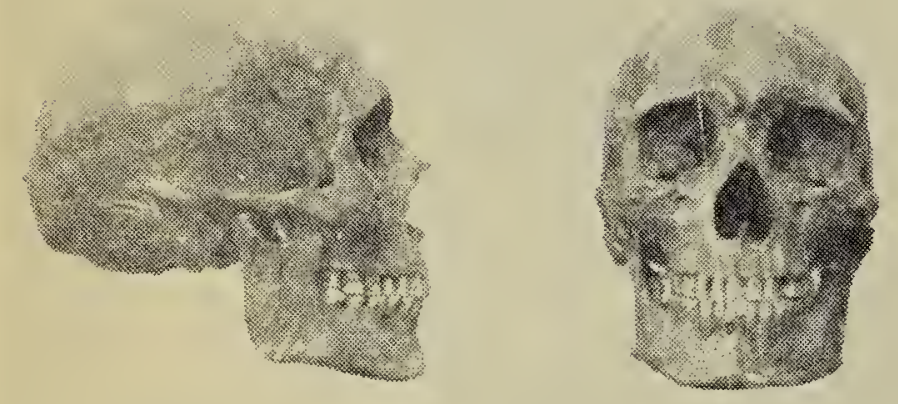

b

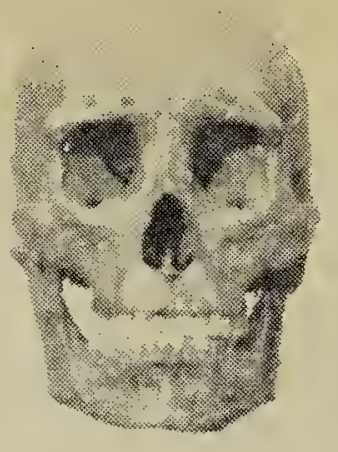

Fig. 3. Adult skulls from Bracken Cairn: BG-1 (Male) above, BG-2 (female) below. check points for a male skull. When compared to BG-2, we find the bone in most instances is much heavier, the muscle tugs more prominent, brow ridges and temporal ridges prominent, teeth large. BG-2 contrasts in thickness of bone, prominence of muscle attachments, temporal ridges and general characteristics, the whole structure of the cranium being somewhat smaller and more delicate, although her prominent supra-orbital brow ridges tend to confuse the issue. A possible explanation is that the female Australoid skull often bears brow ridges as prominent or more so than the average male white skull. Both skulls have a cephalic index of less than 75, are both dilochocephalic, or longheaded, and therefore fall into the Australoid category, which would help to explain the brow ridges of the woman.

Comparative measurements are as follows:

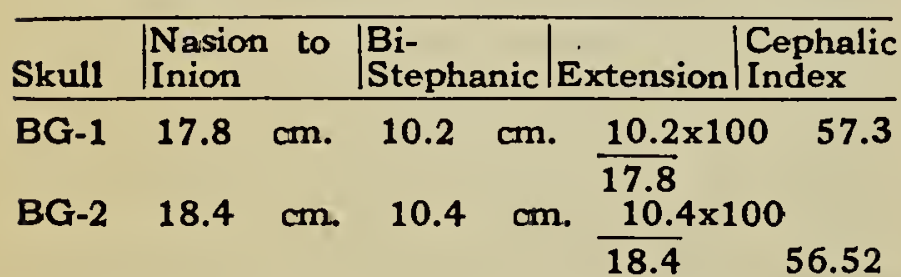

Mandibles-The mandibles of both skulls are striking in appearance, being very large, square jawed and heavy boned. One mandible (BG-1A) is heavier and has: more prominent muscular attachments. Presumably it is male. From actual physical contact it was found to fit BG-1 better than BG-2; and the other mandible, BG-2-A seems to articulate properly with the female skull.

Teeth-The teeth of both skulls, maxillae and mandibles, are in excellent condition with no cavities evident. The cusps of all teeth have been worn off flat, probably through a diet of gritty foods. Teeth in both skulls meet evenly and squarely. The teeth in skull BG-1 appear appreciably larger than those in skull BG-2.

Infant Skull-A third, fragmentary, skull, separated at the sucures and with the plates badly broken up, is that of an infant. It is not definite where the specimen was found, but several teeth, undoubitedly from this skull, were recovered, along with portions of the cranium and what may be a finger or toe bone.

Long Bones-Evidently when the grave was first opened the skeletons were complete, but on the second excavation, in 1948, most of the long bones were found to be smashed or crushed by the weight of stones upon them. Mrs. Wright did recover some, 
however, including a femur, two humeri, several vertebrae and a portion of pelvis. By comparison, the two humeri are quite dissimiliar, one being noticeably larger than the other, with more prominent muscle tugs. This tends to differentiate between male and female, but there is no necorded association with the skulls. The pelvis and one humerus are thickly coated with red ochre, suggesting the painting of bones as mentioned above.

\section{OSTEOLOGICAL MATERIAL}

Osteological materials other than human, necovered firom the grave and identified by Dr. Robert Nero and Bruce A. McCorquodale of the Saskatchewan Museum of Natural History are:

Swift (Kit) Fox-Mainily mandibles and sheared maxillae.

Pronghorn (Antelope) - One horn core and portion of cannon bone.

Deer-One tip of antler, possibly intended or used as flaking tool.

Two burrs from antlers, hollowed out.

Bear-Teeth and portions of maxilla, out for ornament.

Bird-One large bind bone, unidentified, with small nound holle drilled near ane end.

Bison-One tooth.

Beaver-Portion of two incisors.

Skunk-Skull (complete).

Metal-Only one piece of metal was found in the burial, that being a small folded copper bead. The copper is probably native and need not suggest White contact.

Shell Material-Most significant of the shell materials are the large gorgets, which signalled the discovery, and three beads. One gorget and one bead are shown in Fig. 1. Similar material has been recovered from a bog near Dundurn, Saskatchewan. (Through personal correspondence with Nero, 1960, it was learned that two gorgets and a projectile point closely comparable with the Bracken material were found in a bog near Dundurn and are now in the Royal Ontario Museum.)

Bone Material-A number of interesting bone antifacts were uncovered in the burial. One appears to be a representation of a bear claw, being tapered to a crescentic shape and flattened on all four surfaces with definite square edges (Fig. 4-C). It is unperforated and shows grinding marks. Many edges are polished from wear. Nero suggests that it may be a kind of flat awl. This item, cut from a very heavy piece of bone, has taken on a stained ivory coloration.

A group of seven smaller bone objects, obviously pendants, are also carved of heavy bone, pear shaped, with tapered holes drilled through the small end. They are very suggestive of representation of elk teeth, although flattened to a plano-convex section, perhaps owing to the curvature of the original bone from which they were carved. As with the 'bear claw', they exhibit fine scratches of filing or grinding but are well polished on the convex face (Fig. 4-D).

Two badly decomposed pieces of bone may be spatulas or quill flatteners. One (Fig. $4-\mathrm{g}$ ) is the tip only of a broad, thin tool, rounded at the end and showing wear. The other is a section of split mammal rib, narrow and flattened on the surface, with the cancellous material removed. Weathering has destroyed any trace of working or wear (Fig. 4-h).

Two burrs from the antlers of deer have been cut short and hollowed out to form small containers. One is shown in Fig. 4-a. They retain no trace of substance to show what they contained, whether paint, grease or artifacts.

Probably the only definitely recognizable bone artifact is an awl cut from a section of heavy bone, well worked to a point and polished, having the same old ivory colouring as the bear claw and pendant (Fig. 4-k).

At least one beaver incisor was recovered, in fragments. It shows much wear at one end, and was used probably more as a chisel than as a graver in the usual manner (Fig. 4-i).

A portion of the maxilla of a bear, with several teeth intact, has been cut and shaped on one side, but no definite use can be stablished.

Ochre-Hematite or red oxide of iron is present all through the burial. A thick layer of colour is shown in the profile of the excavation and in some places apperars to be two or three inches thick. Evidently the hole was filled in above the bodies, and ochre spread over a wide area at the original ground level, after which 

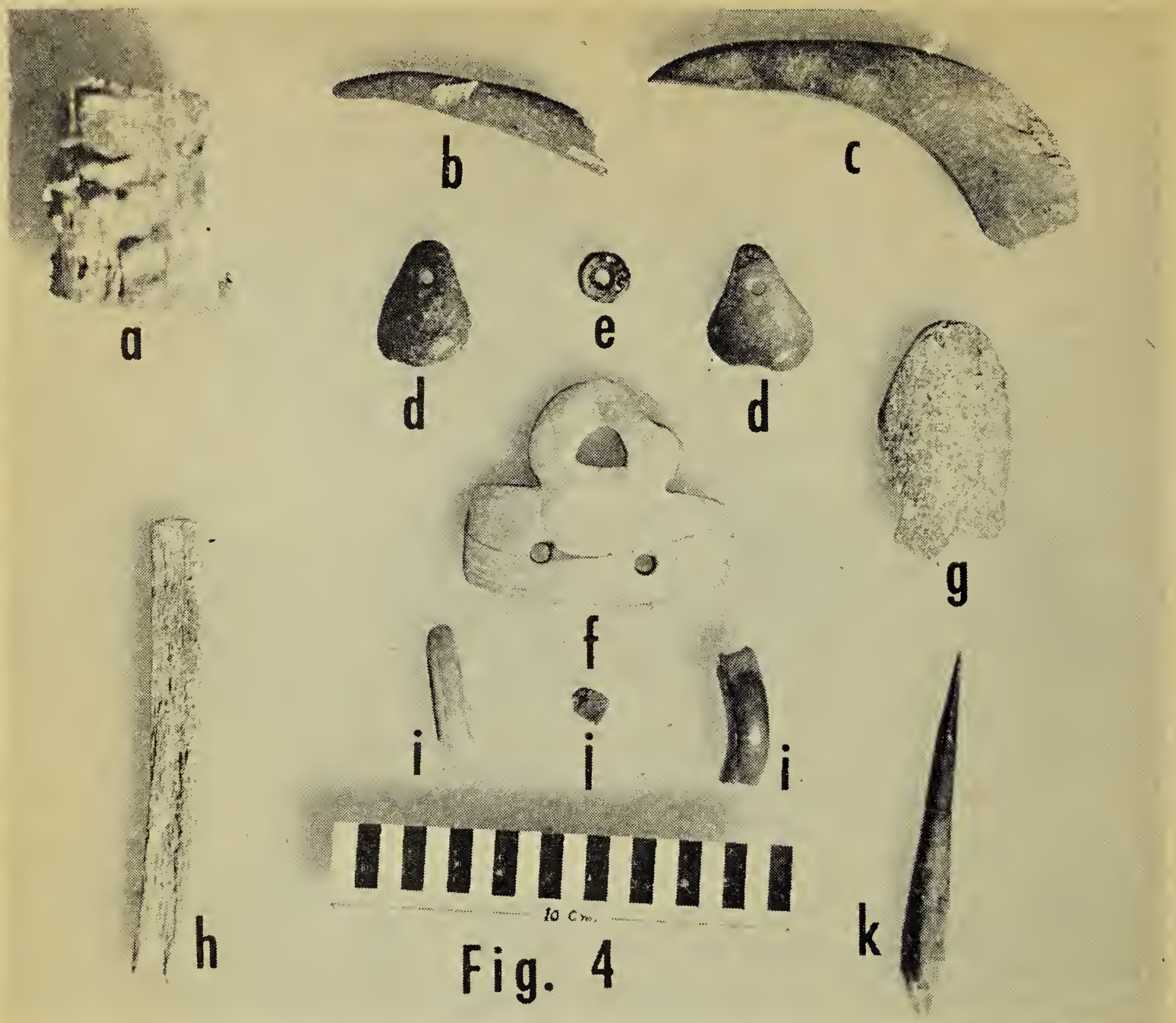

Fig. 4. Shell and bone material from Bracken Cairn.

stones were piled on top. The line of colour extends well past the outline plan of the burial (Shown by dotted lines in Fig. 2). A good deal of colour has leached down to colour the earth and sand around the remains, and was concentrated enough to stain some of the bones and artifacts. Certain parts of the skeletal remains, however, appear to have been coated deliberately with hematite. Large quantities of coloured sand were observed in situ and some samples saved for reference and study.

Limonite, or yellow oxide of iron, is present in somewhat smaller quantity. A few small lumps were recovared, but its use in the burial has not been determined.

\section{CHIPPED STONE ARTIFACTS}

Projectile points-The only projectile point found with the burial (Fig. 5-a), is a heavy plano-convex piece, with one slightly barbed shoulder and wide corner notches.

It is made of grey granitic material with poor knapping qualities. The base is deeply convex and ground.

Measurements of the point:

Length $36 \mathrm{~mm}$.

Length of blade ............ $29 \mathrm{~mm}$.

Width at shoulder ...... $22 \mathrm{~mm}$.

Depth of notch .............. $4 \mathrm{~mm}$.

Width of neck .................... $13 \mathrm{~mm}$.

Width of base .................. $17 \mathrm{~mm}$.

Thickness .............................. $5 \mathrm{~mm}$.

This point may be favourably compared with Pelican Lake points from the Mortlach site (Wettlaufer, 1956:107), which have been estimated at 800 B.C. However, Forbis points out certain characteristics common to point types from the lower members of the Old Woman's Jump (Forbis, 
1959) (Fig. 5-b). The Bracken point appears more closely related to the Old Woman type than Pelican Lake, but these two types are different only in a few respects and are nearly contemporary. The Bracken point could belong to either group, or both.

Evien though this point compares favourably with points from the Old Woman's Jump (ca. 1650) (dated by Carbon 14 tests of material from the site), we cannot presume that the burial itself is of a like antiquity on the basis of a single specimen.

Drills - This category is also represented by a single specimen. Made from Knife River flint, the drill measures $3.8 \mathrm{~cm}$. in length, two $\mathrm{cm}$. across the widest part of the base. It is a typical specimen, being well formed, flaked on all faces and edges, with concave body edges and full convex base. The tip is missing (Fig. 6-j).

Scrapers-The collection contains a number of well-made end scrapers, of which five are shown in Fig. 6 (c to $\mathrm{g}$ ). Two are of fine yellow jasper and two smaller ones of Knife River flint, of which one is well into the process of patination. All five are the so-called 'snub-nosed end scrapers', although one (Fig. 6-c) is somewhat of a departure from the common type, being a large spall worked to a side scraper on the long edges, and an end scraper on one blunt end, in reality a dual purpose tool. All end scrapers show considerable wear on the bit end.

Side scrapers (Fig. 6-a-b-h-i-m) occasionally overlap or become dual purpose tools. Some of the thin unifacially worked flakes have suggestions of fine bifacial retouch in places, as for knives. Here again there is much wear on the edges.

Biface Tools-In the series of seven well-made bifacially worked tools (Fig. 7), two, No. 7-c and No. 7 -d take the form of definite ovates, made of red quartzite, and corresponding in shape although varying greatly in size.

Pear-shaped variants of the ovate biface are very thin in comparison to the others (Fig. 7-d, b, g). There. are cruder ovates. One is a well shaped blade, possibly unfinished at the narrow end; it has a rough len-

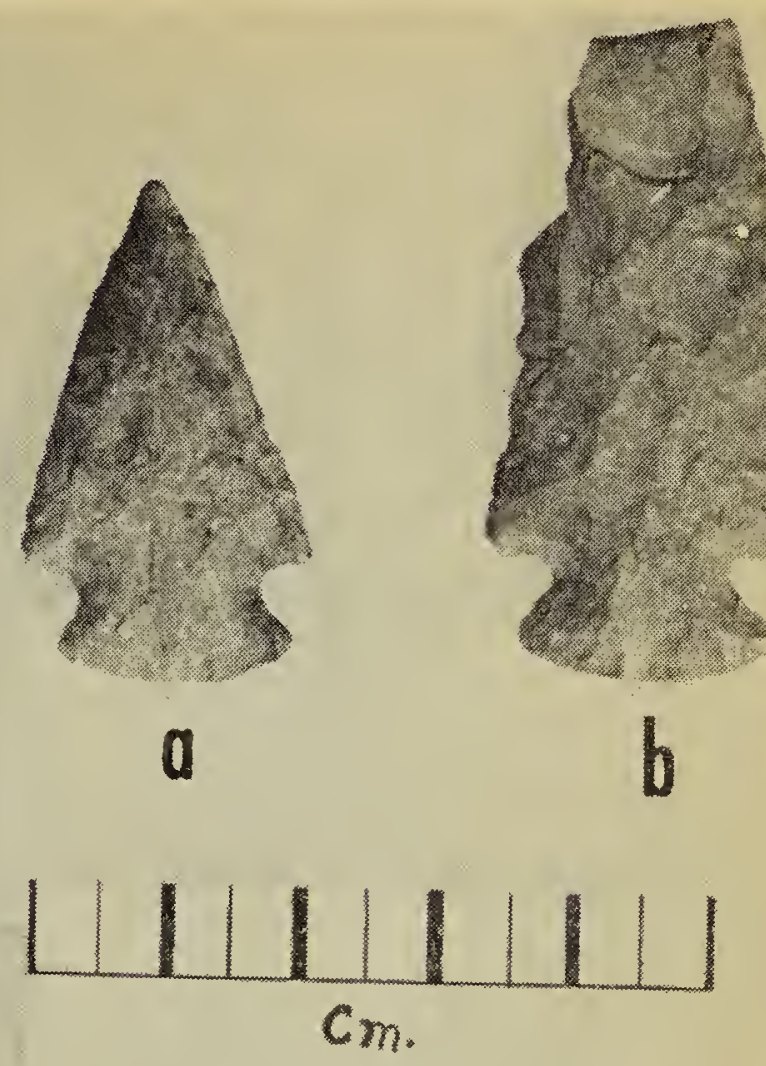

\section{Fig. 5}

Fig. 5. Projectile points from Bracken Cairn (left) and from Old Woman's Buffalo Jump (right).

ticular section and takes the form of an elongated ovate (Fig. 7-f).

Note: All of the above bifaces appear to be common in southern Saskatchewan, to judge by the collection made in the Mortlach area by Kenneth Jones. They also correspond to types found in Central Alberta by Hugh Bower of Red Deer.

\section{GROUND STONE ARTIFACTS}

The single ground stone artifact is a pestle (not illustrated). It is well polished on the stem and sides of the head, but the face and one side of the head show either deterioration or wear by percussion. Robert Nero and his associates believe that it is made from stalagtitic material.

\section{UNWORKED STONE}

The grave contained a number of flakes and chips of various materials which show no working. Material represented include chert, jasper, Knife River flint, quartzite and petrified wood. 

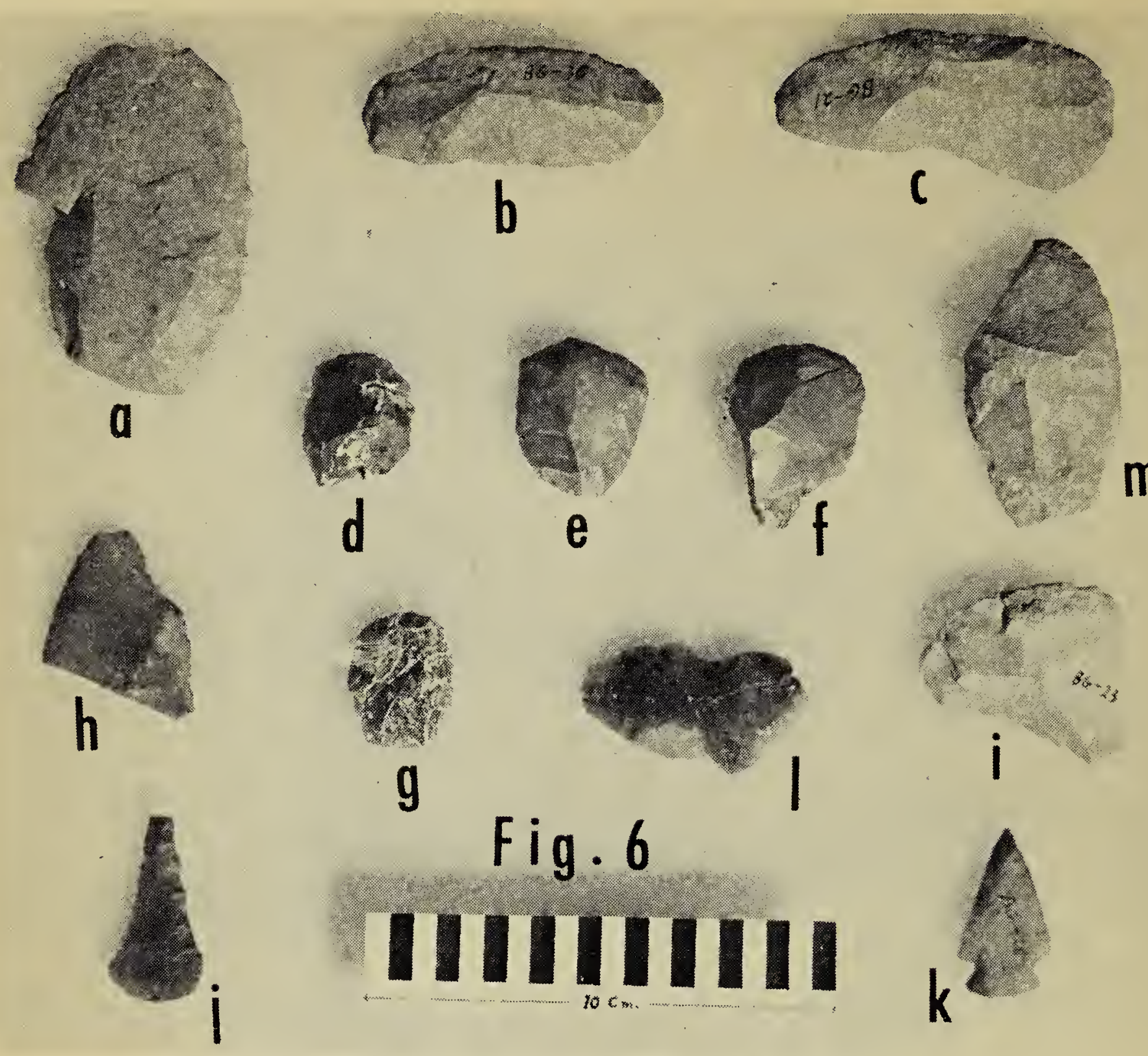

Fig. 6. Drills and scrapers from the Bracken Cairn.

\section{SUMMARY}

From the evidence studied the following possibilities are suggested:

1. The grave contained the remains of an adult male, an adult female and an infant.

2. The man was buried first. At the time of his death he was about 27 years old. He may have been originally buried on a scaffold or in a tree, or some other form of exposed burial; and at some later time his family gathered his bones, painted them with red ochre and reburied them on the hill, marking the place with a pile of stones.

3. The woman, passing him in age after his death, may have been a relative. She died some time after the age of 36 and was also exposed to the elements, after which her remains in turn were gathered by her family along with those of her child, and taken to the site on the hill, where the grave was opened and a second hole dug close beside the first, the bones placed, and the hole again filled and covered with stones. Token possessions were scattered over the bones on interment.

4. The date of interment may be about the time of Christ, to judge by the projectile point. At any rate the absence of pottery indicates an early date, while the fact that there is no trade metal or glass shows the burial to be at least pre-contact.

5. The similarity of some material from the Bracken Cairn to other complexes in Saskatchewan suggests the possibility that the Bracken Cairn may repnesent an example of the burial rites of an Archaic culture with affinities with Pelican Lake complex as at Mortlach site (Wettlaufer, 1956) and possibly Long Creek site (Wettlaufer, 1960). 

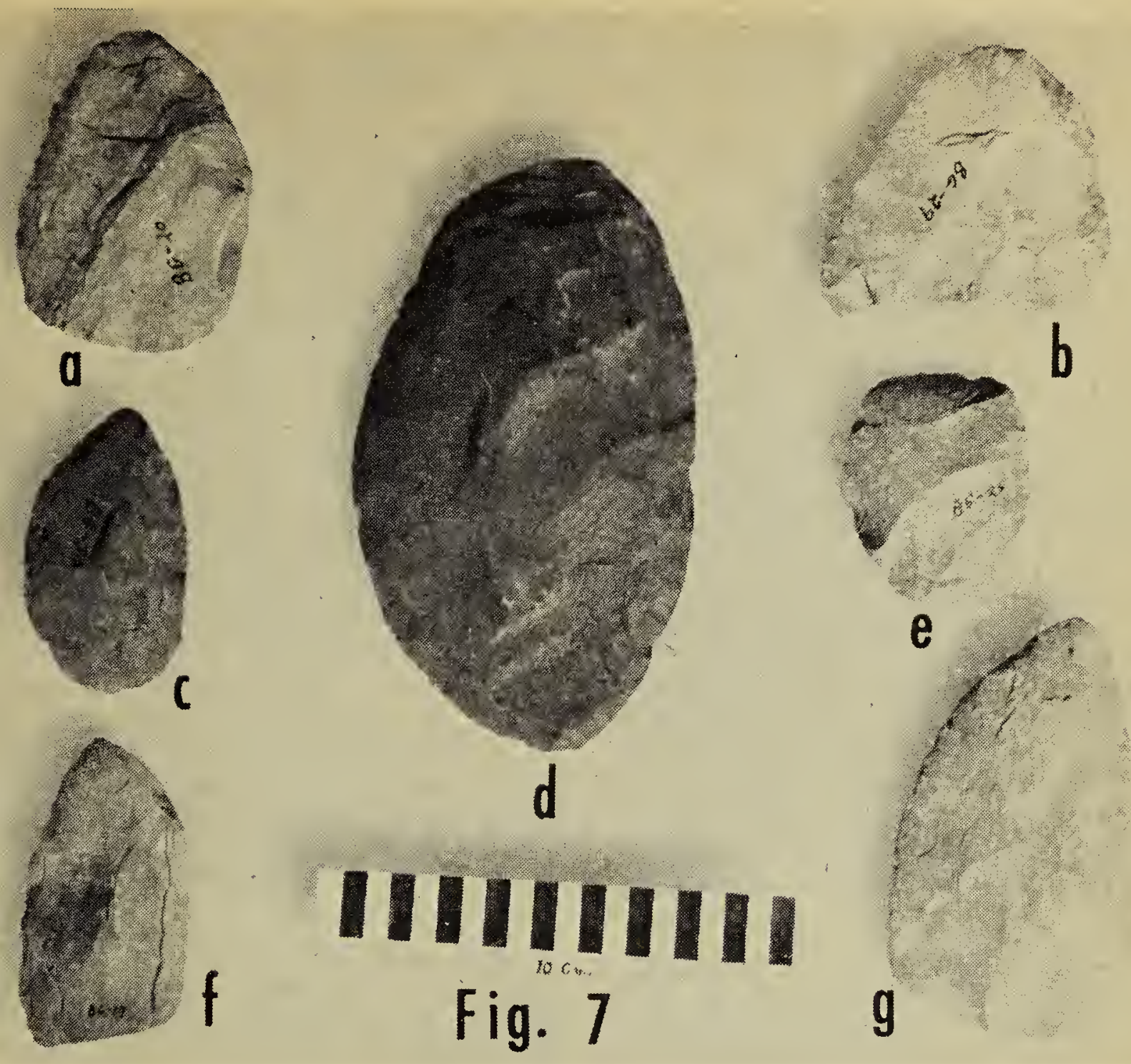

Fig. 7. Bitace tools from the Bracken Cairn.

\section{ACKNOWLEDGMENTS}

I would like to thank Dr. Robert W. Nero and Bruce A. McCorquodale, Saskatchewan Museum of Natural History, for their co-operation in relaying information and identifying osteological material; Dr. Richard Forbis of the Glenbow Foundation, Calgary, for his encouragement and criticism; and above all, Mrs. Laura Wright of Bracken, for her patience and willing co-operation for supplying the burial material for the project.

\section{LITERATURE CITED}

Forbis, R. G. 1959. The Old Woman's Buffalo Jump, MS. Glenbow Foundation.

Lowie, Robert H. 1954. Indians of the Plains. Anthropological Handbook No. 1. The American Museum of Natural History.

Smithsonian Institution. 1910. Handbook of American Indians north of Mexico. Bulletin No, 30.

Todd, T. W. and D. W. Lyon. 1954. Endocranial suture closure, its progress and age relationship. Basic readings on the identification of human skeletons: estimation of age. Wenner-Gren Foundation for Anthropological Research, Inc.

Wettlaufer. B. 1956. The Mortlach site in the Besant Valley of Central Saskatchewan. Anthropological Series No. 1. Department of Natural Resouroes, Regina, Sask.
Wettlaufer, B. 1960. The Long Creek Site. Anthropological Series No. 2. Saskatchewan Museum of Natural History, Department of Natural Resources, Regina, Sask.

\section{CO-OPERATIVE SPRING MIGRATION STUDY}

Observers throughout the continent are again participating in a spring migration study for a selected list of species of birds carried out under the auspices of the U.S. Fish and Wildlife Service. Members of the Society ane urged to keep migration dates and submit their records for species listed in the March, 1960, Blue Jay (add Tennessee Warbler, Blackpoll Warbler, Bobolink) to C. Stuart Houstou, 2401 Hanover Ave., Saskatoon. 